\title{
As Manifestações do Raciocínio em uma Sequência Didática Sobre Função com o Auxílio de um Software
}

\section{The Manifestations of Reasoning in a Didactic Sequence about Function with the Support of Software}

\author{
Antonio Sales ; Kátia Guerchi Gonzales*bc \\ anniversidade Anhanguera-Uniderp. MS, Brasil. \\ bUniversidade Estadual de Mato Grosso do Sul. \\ 'Universidade Anhanguera-Uniderp, Programa de Pós-Graduação Stricto Sensu em Ensino de Ciências e Matemática. MS, Brasil. \\ *Email: profkatiaguerchi@gmail.com
}

\begin{abstract}
Resumo
Este trabalho é um recorte do relato de uma pesquisa experimental com o uso do software Graphmática. O experimento deu-se através de uma sequência didática com estudantes do ensino médio de uma escola pública de Campo Grande, MS. A metodologia utilizada foi a dialógica e teve por objetivo analisar a contribuição do software e da dialogia para fazer emergir os raciocínios classificados por Peirce como abdutivo, indutivo e dedutivo. Os resultados indicam que essa possibilidade existe, mas requer mais tempo de convivência com os estudantes para conquistar confiança e corrigir algumas fragilidades decorrentes da pouco familiaridade deles com a tecnologia de bancada, bem como, alguns vícios de notação e comunicação verbal construídos durante a vida escolar.
\end{abstract}

Palavras-chave: Graphmatica. Abdutivo. Indutivo. Dedutivo. Educação Matemática.

\begin{abstract}
This work is a cut of the report of an experimental research with the use of the software Graphmática. The experiment was carried out through a didactic sequence with high school students from a public school in Campo Grande, MS. The methodology used was the dialogic, which had as objective analyze the software's contribution and the dialogism to emerge the reasonings classified by Peirce as abductive, inductive and deductive. The results indicate that this possibility exists, but it requires more time with the students to gain confidence and to correct some weaknesses due to their lack of familiarity with bench technology, as well as some notation and verbal communication habits built during the school life
\end{abstract}

Keywords: Graphmatica. Abductive. Inductive. Deductive. Mathematical Education.

\section{Introdução}

Em suas contundentes observações, Penteado (1999) mostra-nos que em 1980, com o aperfeiçoamento dos computadores pessoais, debates sobre a introdução de computadores no âmbito escolar foram potencializados. $\mathrm{Na}$ época, essas iniciativas se manifestaram de diversos modos, nas escolas. Penteado cita-nos duas formas dessa manifestação: uma delas é a inclusão no currículo de uma disciplina de informática, para que os estudantes se apropriassem da linguagem e manipulação de alguns softwares e tivessem acesso à internet, entre outros. E a outra, deve-se ao trabalho com o computador junto às disciplinas do currículo.

A autora discute ainda que mesmo com as escolas equipadas com computadores, era grande o número de docentes que não utilizavam o computador como aliado no ensino e aprendizagem dos estudantes. As dificuldades para essa incorporação eram decorrentes das alterações no âmbito das relações bem como nas condições de trabalho, na dinâmica das aulas, nas organizações do currículo, etc.

No entanto, reforça essa autora, que a presença do computador provoca um novo ritmo nas aulas por parte dos docentes como dos discentes, pois o professor não traz apenas mais um recurso para sala de aula para auxilia-lo nas resoluções de problemas, mas também, inaugura outro canal de comunicação com os estudantes.

Tais discussões, atualmente, ainda são pertinentes para o cenário educacional brasileiro. Deve-se ressaltar que o termo "inclusão digital", como destacado por Bairral e Abreu (2009), não se resume apenas em ter computadores e internet disponível para os estudantes, mas especialmente, na apropriação da tecnologia e a possibilidade de engendrar conhecimentos com a ajuda desses objetos educacionais.

Vale ressaltar ainda que não somente as tecnologias informáticas tem ocupado espaço dentro das escolas, como também, a formação inicial e continuada de professores tem sido tema de destaque e foco de políticas públicas que visam a inclusão digital. De acordo com Bairral e Abreu (2009) os estudos, em países desenvolvidos, que se debruçam no tema de inclusão digital tem observado o trabalho dos professores com o uso de determinados software em suas aulas. Os resultados desses estudos mostram que há duas formas do trabalho: a primeira, muito utilizada em escolas com o perfil socioeconômico baixo do alunado, visa o trabalho com exercícios, prática e domínio das ferramentas 
básicas; a segunda, mais trabalhada em escolas de maior poder aquisitivo, foca em processos de raciocínio complexos e inovadores. Contudo, no Brasil, esses estudiosos observam que a inclusão digital pode ser feita por meio das seguintes vertentes: nas interações dos discentes em contextos mediados pelas Tecnologias Digitais de Informação e Comunicação (TDIC), na qualificação profissional de jovens e adultos para trabalhar com a informática e no desenvolvimento do conhecimento docente para o ensino da matemática. Nesta vertente as TDIC são mediadoras. O presente estudo coopera com resultados para a implementação de uma proposta de ação docente visando processos de raciocínios complexos e inovadores.

Para esta pesquisa, baseada nas definições de raciocínio propostas por Charles Sanders Peirce (1839-1914), procurouse desenvolver uma sequência didática, com o uso do Software Graphmática, com o objetivo de avaliar a possibilidade da utilização do mesmo para uma aula dialogada onde o estudante seja provocado a testar hipóteses e argumentar, exercitando, dessa forma, os juízos perceptivos a saber: a dedução, a indução e a abdução. Como esses juízos, segundo o autor, se manifestam nos fatos da experiência, não são passíveis de análise, mas apenas de constatação e utilização. São eles que manifestam a complexidade das relações que o sujeito estabelece no interior do objeto estudado. Entendendo que o presente estudo refere-se a uma dimensão de estudo da Matemática e desenvolvimento do raciocínio, cabe-nos, inicialmente, realizar uma reflexão sobre essa perspectiva.

\section{O Estudo da Matemática}

Estudar Matemática é disciplinar a inteligência escreveu Toranzos (1963). Esse é o seu valor formativo e está condicionado ao modo como os processos de ensino e de estudo são conduzidos. Assumimos que estudar e ensinar são aspectos diferentes do mesmo processo. Enquanto ensinar é ação direta do professor e, tradicionalmente, está centrado nele, estudar é ação do aluno. No entanto, os dois podem se complementar, sendo que o mais importante é o estudo. A ênfase no estudo justifica-se por ele carregar em si os conceitos de envolvimento no processo e autodeterminação.

Ao falar em estudo como ação do estudante não se pode ignorar que essa palavra pode ter conotações diferentes de acordo com a perspectiva teórica da ação docente. Estudar pode ser um verbo que se limita ao cumprimento de tarefas elaboradas como forma de reforço do que foi abordado em sala de aula. Por outro lado, essa ação pode ter um significado mais amplo como, por exemplo, uma prática norteada por uma teoria que a torna eficaz. Nessa perspectiva, estudar é um processo metódico que ocorre em seis momentos, não necessariamente sucessivos, que consiste em dar-se conta de que existe um problema a ser resolvido, uma ideia a ser apropriada ou entendida ou uma técnica a ser dominada. Em seguida dá-se conta de que há a necessidade de uma técnica de estudo ou uma técnica matemática para resolver o problema com o qual se deparou. O terceiro momento é vivido quando se encontra uma justificativa matemática, social ou psicológica para assumir-se envolvido na resolução do problema, para depois vir a aplicação da técnica definida. Essa aplicação pode se dar com a orientação do professor ou não. Aplicar a técnica é o momento da ação procedimental, quando ocorre a mobilização dos conhecimentos ou da vontade para atacar diretamente o problema. O quinto momento, denominado de institucionalização, ocorre quando se articula a ação praticada com as normas cultas, com as regras vigentes. E o sexto momento consiste na avaliação e aperfeiçoamento da técnica utilizada. Avaliar a técnica não só no sentido de referendála pela teoria, mas também de discutir a sua abrangência e pertinência. Os dois últimos momentos não serão considerados na análise deste trabalho tendo em vista o tempo reduzido de sua aplicação (Chevallard, Bosch, \& Gasón, 2001).

Fausto Toranzos pertence ao grupo de educadores matemáticos que pressupõem haver uma forma correta de raciocinar e que a Matemática contribui para que essa forma seja estabelecida. Para esses educadores, esse valor educativo da Matemática justifica a sua presença no currículo da educação básica. Estudar Matemática é educar-se para bem conduzir o pensamento e desenvolver a inteligência. É um modo de olhar a sociedade como uma estrutura bem organizada e fadada ao sucesso. Sucesso aqui entendido como tendo chegado a termo, portanto, o estudo da Matemática busca orientar-se pela regularidade e previsão de desfecho. Outros educadores partilham de pensamento diferente e supõem que a Matemática, apresentada na sua forma clássica, seja um condicionante do pensamento no molde europeu, portanto, algo questionável. Este segundo grupo pensa na constituição do pensamento crítico, capaz de olhar a sociedade pelo viés das suas imperfeições, carências, tendências indefinidas e necessitando de uma reorganização constante.

De qualquer forma os dois grupos concordam com o potencial da Matemática para estruturar um modo de pensar. Divergem com respeito ao valor que atribuem a essa particularidade. Este trabalho se direciona pela primeira perspectiva: observação de regularidade e previsão de desfecho.

O educador matemático brasileiro, Euclides de Medeiros Guimarães Roxo (Roxo, 1937) que exerceu influência na elaboração dos programas de Matemática na Reforma Educacional Gustavo Capanema, cultivava o pensamento que norteava as discussões internacionais da época. Pensamento do qual Toranzos era herdeiro.

Roxo defendia a Matemática como um paradigma para o pensamento lógico. Neste trabalho assumimos, com Roxo e Toranzos, que esse potencial da Matemática para construir uma forma de pensar deve ser valorizado. Entendemos que para que se possa proceder a uma análise crítica do modelo social vigente é necessário que se aproprie de um referencial. 
Nessa perspectiva, as tendências indefinidas que necessitam de reorganização constante são mais facilmente percebidas a partir de um modelo estabelecido historicamente. As regularidades, quer no mundo físico, biológico ou social precisam ser percebidas para que, a partir dessa percepção, se proceda a avaliação ou previsão.

Considerando que este estudo está fundamentado nos tipos de raciocínios propostos por Peirce (1989), estes são abordados a seguir.

\section{Os Raciocínios na Perspectiva de Peirce}

Fundador da corrente pragmatista, Peirce (1989), foi um pensador original que influenciou a área de comunicação e da linguística. Formado em Física, Matemática e Química desenvolveu pesquisas geodésicas, atuou no laboratório astronômico de Harvard e como conferencista de lógica na Universidade Johns Hopkins. O seu pragmatismo, depois pragmaticismo, levou-o a formular a classificação dos fenômenos em três categorias sendo que argumento pertence à categoria da "terceiridade" ou de terceira ordem porque é a racionalidade da experiência. É quando um fenômeno, deixa de ser singular e passa a significar alguma coisa para alguém. Extrapola o sensível e se insere na esfera do pensamento, do simbólico; é um "legissigno" (signo convencional), isto é, deixa de ser coisa para ser convenção. As palavras, uma pintura e os símbolos matemáticos são exemplos de terceiridade. A secundidade seria constituída pelas relações que tais fenômenos estabelecem entre si como, por exemplo, isto aponta para aquilo ou indica isto (D'Oliveira, 1989; Braga, 1999; Coelho Netto, 2014), sem discutir as relações causais.

É o fato de existir uma terceiridade na experiência que torna possível o conhecimento, porque este resulta dessa racionalidade; dessa possibilidade de se estabelecer uma lei. Nas suas conferências sobre pragmatismo Peirce dedicou-se em definir os tipos de raciocínios. Primeiramente ele trata do juízo perceptivo como aquele que se fundamenta em fatos, como perceber a subsequência de um evento em relação a outro. A ocorrência deles, no entanto, não depende do outro ter ocorrido. É a primeiridade dos fenômenos. É a singularidade deles porque estão limitados à existência, à análise em nível do juízo perceptivo. No entanto, ele admite a subsequência aparente. É o caso do paradoxo de Aquiles e a tartaruga em que a corrida não precisa acontecer para que se perceba que ele a alcançará. Nesse caso, não é necessário que se faça uma análise crítica, fundamentada em alguma premissa para deduzir uma proposição universal. Primeiridade é a qualidade dos fenômenos como a cor, a altura, etc.

Com isso Peirce nos conduz às três categorias que devem ser estudadas: ícone, (primeiridade), índice (secundidade) e símbolo (terceiridade) ou qualidade, relação e representação.

$\mathrm{Na}$ primeiridade, segundo Martins (2015), o outro só existe em potência. Ou ainda:
A experiência de primeiridade leva em consideração o signo em si mesmo; a impressão de qualidade, a captação do fenômeno de maneira espontânea ou imediata. Então, a ideia é a primeiridade (ícone). Já a experiência de secundidade é a construção do signo, a consciência da parte inserida no todo, a relação com a materialidade, com a exterioridade; o signo é considerado na sua relação com o objeto e este é a secundidade (índice). A terceiridade (símbolo) faz a ligação entre a primeiridade e a secundidade, permitindo uma interpretação do mundo. (Moimaz, \& Molina, 2009, p.579).

Ele define então três tipos de raciocínio: dedutivo, indutivo e abdutivo. Deduzir é, segundo Peirce, partir do geral, do que está definido abstratamente, de hipóteses formuladas a partir das características que relacionam as premissas com a conclusão. $\mathrm{O}$ raciocínio indutivo, na perspectiva desse pensador, é, por sua vez, "um processo de investigação experimental", sendo que experiência não se limita à manipulação de objetos, mas é uma suposição, uma questão posta à Natureza. Mais especificamente, experimentar é formular uma sequência de questões a partir de cada afirmação obtida. Cada vez que a teoria é confirmada formulase nova questão resultando desse modo em certo número de "testes experimentais" que corroboram a hipótese formulada (Peirce, 1989, p.14). A indução, portanto, é precedida pela "hipótese explicativa" resultante de um ato instintivo racional denominado abdução.

Eco (1989, p. 161) discorre sobre a abdução denominando-a de "rapinagem", algo como raciocinar por analogia, tomar "emprestada uma lei" proveniente de outro lugar. Se o que está acontecendo fosse produto do acaso o resultado seria outro, pondera o sujeito ao raciocinar abdutivamente. É o raciocínio abdutivo que aproxima o artista do cientista, pondera Eco. Santaella (2004, pp. 94-100) denomina a abdução de "raciocínio de trás para frente" e "inclui elementos não observáveis tanto quanto fatos observáveis", é uma antevisão lógica do que poderá acontecer. Segundo essa autora a abdução, apesar de instintiva é uma inferência lógica e segue alguns passos: “a) observação criativa de um fato; b) uma inferência que tem natureza de uma adivinhação; c) a avaliação da inferência reconstruída". Ela nos conduz "provisoriamente a uma regra geral". Abdução e indução seguem caminhos opostos. Abdução parte da experiência para a hipótese e a indução, da hipótese para a experiência. Abduzir é superar a primeirtidade, é ver indícios, enquanto indução é a superação da secundidade, a busca pela abstração, pela construção de uma regra geral.

\section{Função}

Muitos conceitos da Matemática são utilizados em diversas situações do cotidiano. Dente esses destacamos o conceito de função presente em situações, como por exemplo, o consumo de combustível de um automóvel, a concentração de álcool no sangue de um indivíduo após a ingestão de bebidas alcoólicas, o valor de uma conta de energia elétrica, entre outras. Dizendo em outras palavras: função é o estudo da variação e da relação 
entre dois fatores codependentes.

A importância do estudo das funções baseia-se no fato de que esse tema permeia, de forma explícita ou implícita, todos os demais temas da Matemática. Na perspectiva da educação levar o aluno a reconhecer que as situações-problema, oriundas ou não do cotidiano, podem ser representadas por uma sentença matemática é um dos objetivos do ensino da Matemática. Segundo os Parâmetros Curriculares Nacionais (PCN), um dos objetivos da presença desse estudo para o quarto ciclo, é propiciar o desenvolvimento "do pensamento algébrico, por meio da exploração de situações de aprendizagem que levem o aluno a observar regularidades e estabelecer leis matemáticas que expressem a relação de dependência entre variáveis" (Brasil, 1998, p.81).

A compreensão do conceito de função é importante não somente para ser utilizado na aprendizagem de outros conteúdos dentro da Matemática como Cálculo Diferencial e Integral, mas também por ter relevância e aplicação em outras áreas do conhecimento, como a Física, a Química e a Biologia.

No entanto, para o presente trabalho o tratamento do conceito de função teve outra finalidade e, por essa razão, foi abordado a partir do gráfico, com a mediação da Tecnologia Digital, isto é, com ênfase secundária na parte algébrica. Essa estratégia foi adotada em virtude de que é possível visualizar as transformações que estão ocorrendo quando determinada expressão algébrica é fornecida ao computador e foi levado em conta também o fato de que o estudo da relação entre álgebra e geometria, entre uma expressão algébrica e uma figura pudesse contribuir para que emergisse algum dos tipos de raciocínio elencados por Peirce.

\section{A Metodologia da Pesquisa}

Esse estudo foi baseado a partir das propostas dos Parâmetros Curriculares Nacionais (PCN), que observam que o docente deve trabalhar com atividades que provoquem:

[...] habilidades como, selecionar informações, analisa as informações obtidas e, a partir disso, tomar decisões que exigirão linguagem, procedimentos e formas de pensar matemáticos que devem ser desenvolvidos ao longo do Ensino Médio, bem como a capacidade de avaliar limites, possibilidades e adequação das tecnologias em diferentes situações. (Brasil, 1999, p.85)

Assim, sob essa perspectiva, podemos dizer que o Ensino Médio tem um valor formativo, que auxilia na estruturação do pensamento e do raciocínio dedutivo, tornando-se um meio para a interpretação da realidade, possibilitando a formação de uma visão ampla dessa mesma realidade. Desse modo, ao seguir tais recomendações, o docente se compromete com a busca constante pelo aperfeiçoamento profissional, que pode ser contemplada tanto em momentos de discussão e estudo em cursos de formação continuada, como em momentos em que há uso de abordagens inovadoras. E, presente proposta foi na segunda direção, no qual, o pesquisador fez a proposta para o professor regente, e esse, por sua vez, aceitou a empreitada.
Partiu-se das ideias de Ezpeleta, \& Rockwell (1986) e Minayo (2014), de que a pesquisa qualitativa é caracterizada por buscar os seus dados no ambiente natural. Ela supõe o contato direto o prolongado do pesquisador com o ambiente e a situação que está sendo investigada. Os dados coletados são predominantemente descritivos. O material obtido nessas pesquisas é composto de descrições pessoais, situações, acontecimentos; inclui transcrições de entrevistas e de depoimentos, análise de fotografias, desenhos, notas de aula, diário de bordo e extratos de vários tipos de documentos. A preocupação maior é com o processo e não com o produto. $\mathrm{O}$ interesse do pesquisador ao estudar um determinado problema é verificar como ele se manifesta nas atividades, nos procedimentos e nas interações cotidianas. Não é o que aconteceu, mas como aconteceu. Procura-se dar enfoque ao modo como os participantes encaram as questões, a participação deles.

Nesse sentido, a pesquisa desenvolvida se caracteriza como qualitativa experimental tendo em vista que foi desenvolvida uma sequência didática com conteúdo matemático e a participação dos estudantes foi gravada em áudio para análise posterior. A metodologia utilizada foi a argumentação justificatória onde cada passo, cada resposta do estudante foi questionada em busca de uma justificativa para a decisão tomada.

O projeto desenvolvido em uma escola pública de Campo Grande, MS, com estudantes do ensino médio é parte de um projeto maior que foi aprovado pelo Comitê de Ética da Uniderp-Anhanguera. A sequência didática foi desenvolvida no laboratório de informática da escola, com a presença do professor titular da turma, e tendo o Software Graphmática como mediador. O tema trabalhado envolveu funções do primeiro e segundo graus e os estudantes foram convidados a participar. A escolha da escola deu-se pela proximidade com a residência do pesquisador e por ser uma escola de tempo integral, portanto, com maior facilidade para encontrar estudantes com tempo disponível para a experimentação, sem interrupção do seu horário regular de aula.

O software Graphmática por Windows, foi escolhido por trabalhar com duas dimensões e ser eficiente para exprimir graficamente diferentes gráficos em uma mesma tela. Representa desse modo, funções trigonométricas, exponenciais, logarítmas, hiporbólicas, etc. Auxilia, o professor a demonstrar e trabalhar com os alunos com diversas aplicações em Matemática. Possibilita, por exemplo, a construção por parâmetros e inequações, além de, representar gráficos com coordenadas polares ou cartesianas, criando figuras que envolvem funções trigonométricas.

O software utilizado apesar de não ser dinâmico (não pertencer ao grupo da geometria dinâmica) permite a plotagem concomitante de diversos gráficos e cada um, automaticamente, surge com uma coloração diferente permitindo que se distinga facilmente um do outro para comparação. Essa particularidade contribui para a discussão 
que se prentendia desenvolver durante a sequência didática deenvolvida. A plotagem das imagens era projetada na parede da sala, por um data show de modo que todos pudessem ver.

Também, escolheu-se o Graphmática por ser um software de uso livre, disponibilizado gratuitamente e de fácil utilização. Além disso, devido o tempo limitado que tínhamos com o desenvolvimento deste trabalho, tornou-se um recurso atrativo, visto que é de fácil compreensão não precisando que os estudantes tivessem grandes conhecimentos de programas ou técnicas refinadas de computação. Nesse sentido, apenas uma simples explicação bastou para que entendessem o seu funcionamento. A opção por esse software voltou-se também para a economia de tempo que teríamos ao representar as retas, focando em um tempo maior para a análise dos resultados.

Todas as atividades trabalhadas com o Graphmática foram elaboradas com aspecto sistemático, de modo que, a resolução de cada atividade tivesse uma regularidade e as respostas fossem gradativas, favorecendo, assim, o estudante registrar, observar e analisar suas compreensões. Esse modo de trabalho, tinha por finalidade, constituir e fixar conceitos sobre o conteúdo trabalhado.

Participaram nove estudantes do Ensino Médio de ambos os sexos, voluntários, e todos eles assinaram o termo de assentimento e em nenhum momento houve constrangimento de qualquer natureza. Este trabalho é um recorte que abrange três sessões de uma hora e trinta minutos, mas de apenas sessenta minutos de trabalho efetivo com os estudantes. Parte do tempo cosnstiu em instalar data show, reinstalar o software nos computadores a cada vez, avisar os estudantes de que sala estava pronta e aguardar a chegada de todos eles que estavam em pontos diferentes da escola. Houve ainda o tempo de desmonatagem do equipamento para entregar a sala de informática ao outro professor.

É importante ressaltar, que a forma de condução da sequência foi a dialogia onde o estudante é provocado a participar opinando e justificando a sua opinião. Nem todos se mostram dispostos a expor o seu ponto de vista, ainda temem o erro e sentem-se inseguros. Foram denominados de E1, E2, etc. e quando não foi possível identificar pela voz denominouse genericamente Ei.

\section{O Desenvolvimento da Sequência e sua Análise}

Uma constatação pouco confortável para nós, enquanto pesquisadores, é, que há alguns estudantes que, apesar de ter contato constante com a tecnologia digital, esse contato está limitado à tecnologia móvel. Eles apresentam dificuldades em manipular o teclado da tecnologia de bancada, como os computadores do laboratório da escola. Não sabem localizar, no teclado, os símbolos usuais da Matemática como a igualdade (=) adição (+) subtração (-) multiplicação (*) e barra de divisão (/). Quando se trata de potenciação (que no software adotado e no Excel é o acento circunflexo) fica ainda mais difícil. A perspectiva de que a mediação da tecnologia torna o processo mais rápido fica prejudicada em virtude dessa pouca familiaridade. Pesquisa recente realizada em uma escola rural do Estado de Mato Grosso do Sul constatou que os estudantes, no período em que não estão na escola, gastam o tempo disponível manipulando o dispositivo móvel e acessando internet, porém, sempre jogando sem nenhuma orientação ou intenção de estudo ou pesquisa. Sem nenhuma sistematização (Santos \& Faria, 2017).

Outra dificuldade encontrada foi a questão da ordem na colocação das variáveis. Mesmo já tendo estudado função, depois das atividades desenvolvidas alguns ainda insistiam em plotar $\mathrm{x}=\mathrm{ay}+\mathrm{b}$, por exemplo. Não ficou claro tratava-se de uma resistência, uma curiosidade ou falta de atenção.

Primeira atividade: tendo plotado as retas $y=x$ e $y=x+1$, levantou-se a seguinte questão: como é possível provar que essas duas retas são paralelas?

Após alguns segundos de reflexão por parte de todos sem nenhuma manifestação, o pesquisador sugeriu que usassem a redução ao absurdo, que tentassem provar que não são paralelas.

Foi esclarecido que recorrer ao recurso da redução ao absurdo significa dizer que quando não se consegue provar que é, tenta-se provar que não é. Como em Matemática seguimos o princípio do terceiro excluído, isto é, que só há duas opções, a negação de uma afirmação equivale a afirmar a validade da afirmação oposta.

Como exemplo do método da redução ao absurdo o pesquisador se propôs a fazer afirmações em favor do não paralelismo das duas retas e eles deveriam mostrar o equívoco das suas afirmações.

Pesquisador: sabemos que o campo visual pode estar nos sugerindo que elas são limitadas (são segmentos de reta). No entanto, não é essa a ideia que se deve ter. Devemos pensar que elas não estão restritas a essa parte visível, que é possível que se prolonguem infinitamente.

Nesse caso, vou supor que em algum momento, fora desse nosso campo visual, elas se interceptam (ou se encontram), e vou supor que essa intersecção acontece no ponto onde $\mathrm{x}=50$.

O que acham? O diálogo está descrito nos Quadros 1 a 7.

Quadro 1 - Diálogo entre o pesquisador e os estudantes durante o desenvolvimento da primeira questão: As retas $y=x$ e $y=x+1$ se interceptam no ponto onde $\mathrm{x}=50$. O que acham dessa afirmação?

\begin{tabular}{|c|c|}
\hline Estudantes & Categoria ou observações \\
\hline $\begin{array}{l}\text { E1: "não se encontram nesse } \\
\text { ponto porque uma delas tem } \\
\text { um número a mais". } \\
\text { E2: por exemplo, uma passa no } \\
(1,1) \text { e a outra no }(1,2) .\end{array}$ & $\begin{array}{l}\text { Dedução uma vez que } \\
\text { perceberam a fórmula geral e } \\
\text { aplicaram a um caso particular. } \\
\text { Dos momentos de estudo } \\
\text { apenas o quinto e o sexto } \\
\text { não se fizeram presentes } \\
\text { explicitamente. }\end{array}$ \\
\hline
\end{tabular}

Fonte: Dados da pesquisa.

As questões seguintes foram: $E$ as retas $y=x-3$ e $y=x+3$ ? E tiveram por o objetivo de orientar como se processa o raciocínio por redução ao absurdo. 
Dados esses passos iniciais apagou-se o "ecrã" e procedeuse retorno à reta $\mathrm{y}=\mathrm{x}$, plotando o seu gráfico, e depois fazendo $y=2 x$ (que significa a multiplicar $x$ por 2 ) sugerindo que não teclassem o "enter", isto é, não mandassem executar.

Quadro 2 - Respondam primeiro a seguinte pergunta: O que vai acontecer com esta reta? Qual a sua relação com a outra? (a outra permanecia no ecrã)

\begin{tabular}{|l|l|}
\hline \multicolumn{1}{|c|}{ Estudantes } & \multicolumn{1}{|c|}{ Categoria ou observações } \\
\hline E1: as duas retas são iguais & Manifestação do raciocínio \\
E2: continuam sendo paralelas & abdutivo. Estavam partindo da \\
E3, E4: retas iguais & experiência para a hipótese. \\
E4: continuam paralelas & Superação da primeridade. \\
E5: a reta é a mesma & \\
\hline
\end{tabular}

Fonte: Dados da pesquisa.

Quadro 3 - Executem o programa. O que aconteceu?

\begin{tabular}{|l|l|}
\hline Estudantes & \multicolumn{1}{c|}{ Categoria ou observações } \\
\hline Ei: não & $\begin{array}{l}\text { Raciocínio não caracterizado. As retas plotadas, } \\
\text { de fato, concorrem na origem do sistema. Os } \\
\text { que disseram que não apareceu nada, olhavam }\end{array}$ \\
nada & $\begin{array}{l}\text { ao longo da reta esperando vê-la aumentando } \\
\text { em comprimento. Haviam abduzido que o } \\
\text { E1: são } \\
\text { concorrentes. }\end{array}$ \\
& $\begin{array}{l}\text { pe qualquer forma os momentos de estudo } \\
\text { foram vivenciados o que é atestado pelo } \\
\text { envolvimento dos estudantes no processo. }\end{array}$ \\
\hline
\end{tabular}

Fonte: Dados da pesquisa.

Seguinte questão: Supondo que seja a mesma reta anterior $(\mathrm{y}=\mathrm{x})$ que sofreu uma alteração, o que aconteceu com ela?

As respostas obtidas ("sofreu uma rotação" e "tem alguma a ver com graus?") teve por base a observação direta e foi necessário que houvesse uma breve interrupção para destacar o fato de existir um ângulo entre elas e esclarecer que a rotação foi no sentido anti-horário.

O mesmo aconteceu quando foi ordenado que substituíssem o 2 por $5(\mathrm{y}=5 \mathrm{x})$ e registrassem, verbalmente, o que aconteceu. A resposta "Continuou rotacionando no sentido anti-horário", se encaixa no mesmo padrão anterior.

Quadro 4 - Substituam o 5 por 100 de modo que fique $y=100 x$. Agora faço uma afirmação: se continuar rotacionando essa reta ela vai coincidir com o eixo das ordenadas (coincidirá com y). O que acham?

\begin{tabular}{|l|l|}
\hline \multicolumn{1}{|c|}{ Estudantes } & \multicolumn{1}{|c|}{ Categoria ou observações } \\
\hline $\begin{array}{l}\text { Ei: não vai coincidir porque se } \\
\text { continuar girando vai passar } \\
\text { para o outro lado. }\end{array}$ & $\begin{array}{l}\text { Manifestação do raciocínio } \\
\text { abdutivo. }\end{array}$ \\
\hline Fonte: Dados da pesquisa.
\end{tabular}

Quadro 5 - Experimentem fazê-la passar para o outro lado. Insistindo é possível fazê-la transpor o eixo y?

\begin{tabular}{|l|l|}
\hline \multicolumn{1}{|c|}{ Estudantes } & Categoria ou observações \\
\hline $\begin{array}{l}\text { E1: vai continuar do mesmo } \\
\text { jeito. }\end{array}$ & Raciocínio indutivo \\
$\begin{array}{l}\text { E2: vai continuar do mesmo } \\
\text { jeito. }\end{array}$ & $\begin{array}{l}\text { Dedução: passaria para o outro } \\
\text { lado se dependesse de y como } \\
\text { depende de x continuará no } \\
\text { "plano" onde x é a primeira } \\
\text { Ei: ela continua no plano } \\
\text { do x., porque podemos por } \\
\text { y=10000x que ela continua } \\
\text { dependendo do } x\end{array}$ \\
\hline
\end{tabular}

Fonte: Dados da pesquisa.
Questão: Diante da pergunta: mas, será que em algum momento ela vai coincidir com o y? Nesse momento houve incerteza geral.

Questão: Vamos supor, por redução ao absurdo, que ela em determinado momento coincidirá com o eixo y. Se isso for verdadeiro o que deverá acontecer no momento seguinte?

Resposta: ficará negativa.

O que se pode afirmar, então?

Questão: Se por esse "caminho" não conseguimos fazêla passar para o outro lado de y (segundo quadrante), qual será o percurso que ela deve fazer para seccionar o segundo quadrante?

Resposta: rotacionar no sentido horário.

Questão: Como fazer para ela rotacionar no sentido horário?

Respostas: E1: "por negativo, colocar número menor".

Tendo em vista que estávamos variando o coeficiente $\mathrm{x}$, a resposta induz obviamente a isso.

Questão: Vamos apagar o ecrã para limpar o "ambiente visual". Coloquem um número menor como coeficiente de $\mathrm{x}$. Será que é possível fazê-la coincidir com o eixo das abscissas (do $\mathrm{x})$ ?

\section{Resposta: "fazendo $y=0$ "}

Considerando que são funções lineares tem-se que $y=0$ é resultado de $\mathrm{x}=0$, mas não se pode afirmar que tenha percebido isso.

Quando questionados como se faria para que ela passasse para o quarto quadrante a resposta foi: "coloca menos um". Essa resposta pode ter sido uma dedução ou simplesmente a revelação de um conhecimento prévio sobre funções.

Quadro 6 - Voltando a $\mathrm{y}=\mathrm{x}$ e supondo que seja ela que esteja girando, pergunta-se: qual a semirreta que está no segundo quadrante? A que estava no primeiro ou que estava no terceiro? Por quê?

\begin{tabular}{|l|l|}
\hline \multicolumn{1}{|c|}{ Estudantes } & \multicolumn{1}{|c|}{ Categoria ou observações } \\
\hline Ei: que estava no terceiro. & Dedução. Se a reta estava \\
E1: porque se fizermos & rotacionando no sentido \\
$\mathrm{y}=1000 \mathrm{x}$ ela se aproxima por & horário, a semirreta que estava \\
um lado e se fizermos y=-1000x & no terceiro quadrante passaria \\
ela se aproxima por outro lado. & para o segundo quadrante. \\
\hline
\end{tabular}

Fonte: Dados da pesquisa.

Quadro 7 - Observe que se fizermos $y=-10 x$; $y=-100 x$ ela vai assumindo a posição vertical. Conseguiremos fazê-la coincidir ao eixo das ordenadas, com o y? Rotacionando no sentido antihorário ela não ultrapassa o eixo $\mathrm{y}$, se rotacionarmos no sentido horário ela ultrapassa o eixo das abscissas. Podemos supor que se continuarmos rotacionando no sentido horário ela ficará girando continuamente até dar a volta completa várias vezes. O que acham?

\begin{tabular}{|l|l|}
\hline \multicolumn{1}{|c|}{ Estudantes } & $\begin{array}{c}\text { Categoria ou } \\
\text { observações }\end{array}$ \\
\hline $\begin{array}{l}\text { E1: não, ela só passa pelo eixo do x, não vai } \\
\text { passar pelo eixo do y. }\end{array}$ & \\
$\begin{array}{l}\text { E2: vai. Quando fizemos ela vindo para lá } \\
\text { [anti-horário] ela não ia passar por causa que é } \\
\text { positivo. A gente conseguiu para cá [horário] } \\
\text { porque começou colocar número negativo, } \\
\text { porque aqui [terceiro e segundo quadrantes] é } \\
\text { tudo negativo. }\end{array}$ & $\begin{array}{c}\text { Abdução. } \\
\text { E1 deduziu e } \\
\text { E2 abduziu. }\end{array}$ \\
\hline
\end{tabular}

Fonte: Dados da pesquisa. 
A discussão seguinte girou em torno dessa problemática da ultrapassagem gerando respostas como esta de E3: eu acho assim: ali a reta do eixo $\mathrm{x}$ ela só passou porque ele é o eixo $\mathrm{x}$ e não tem como trocar de lugar com o eixo y. No eixo y ele passou pelo negativo, mas não tem como passar pelo negativo do $\mathrm{x}$.

$\mathrm{Na}$ realidade, a reta não ultrapassa o eixo das ordenadas em nenhum momento. Tem-se um caso de limite, onde ela se aproxima infinitamente do eixo y sem, no entanto, coincidir com ele. E3 fez uma abdução e a aula teria que ter continuado para permitir testar a hipótese. Os limites de tempo previamente definidos dificultaram e a necessidade de ceder o espaço a outros professores dificulta conduzir uma experimentação até o fim aproveitado as ideias que vão surgindo.

No entanto, foi possível conduzir satisfatoriamente a sequência didática com o apoio do professor titular da turma (fora do seu horário regular) e também contar com a participação efetiva dos estudantes que se mostraram envolvidos no processo, vivendo o momento de estudo que se traduz pela aceitação do desafio de enfrentar o problema proposto. Comportaram-se na perspectiva de estudar. Inclusive o professor interessou-se pelo assunto.

A técnica utilizada foi o debate onde todos tiveram a oportunidade de expressar ou discutir com os seus pares antes que um deles expressasse o pensamento do grupo. Contudo, vale ressaltar que o trabalho do pesquisador, juntamente com o professor de sala de aula foi o de mediador e facilitador, no papel de organizar as tarefas a serem realizadas, tentando minimizar as relações de hierarquia dentro do grupo, para que assim, os alunos sentissem à vontade para opinar e discutir as atividades desenvolvidas. Quando todos os integrantes se mostram compromissados e envolvidos, é que o grupo avança, e foi esse o foco mantido durante todo o processo.

\section{Conclusão}

Iniciamos, nossas conclusões, reiterando que assim como Borba e Penteado (2005, p.37), consideramos que "As atividades [com calculadoras e softwares], além de naturalmente trazerem a visualização para o centro da aprendizagem matemática, enfatizam um aspecto fundamental na proposta pedagógica da disciplina: a experimentação".

A rapidez e a destreza com que o software exibiu as informações gráficas tornou possível abordar integralmente a sequência didática, e ainda ampliou o tempo para as análises e discussões, uma vez que, em sala de aula sem esse recurso, seria necessário um tempo extra para traçar as retas e analisar as conjecturas. Desse modo, destaca-se como resultado positivo, a otimização de tempo. Contudo, apesar da escolha do software também ter sido baseada na facilidade que os estudantes teriam em trabalhar com um recurso que não necessita de grandes conhecimentos de informática, observou-se que demandaria mais tempo para familiarizar os estudantes com a tecnologia de bancada, e principalmente com a metodologia da participação, do questionamento e da liberdade de expressão. Necessitaria mais tempo para corrigir distorções decorrentes de possível da falta de atenção às aulas e para conquistar um nível de confiança que lhes desse liberdade para experimentar, correr o risco do erro, e discutir esses erros. As tentativas nesse sentido não foram frutíferas.

Um fator considerável, é o momento em que os estudantes visualizaram as representações gráficas e as analisaram, pois conforme o previsto e explicito neste texto, foi possível observar movimentos para a construção de conceitos. Nesse sentido, os estudantes por meio da sequência didática foram teorizando e abstraindo, conforme os seis momentos de estudos que nortearam a elaboração das atividades. Primeiro eles perceberam o problema que precisava ser resolvido, verificaram que precisariam de uma técnica matemática para resolver a situação e assim ao visualizarem as retas na tela do computador (momento em que tornou-se possível o acesso ao conteúdo matemático) assumiam-se envolvidos na resolução do problema. Ao aplicar as técnicas perceberam as propriedades matemáticas envolvidas e assim, mobilizaram os conhecimentos, elaborando suas conjecturas.

Outro ponto que pode ser destacado, pois fundamentou a realização deste estudo, deve-se a análise da metodologia abordada por meio do software e da dialogia para fazer emergir os raciocínios explicitados por Pierce. E, após as análises, entende-se que a sequência didática desenvolvida revelou-se potencial, uma vez que todos os casos houve superação da primeiridade o que indica uma vivência explícita dos quatro primeiros momentos de estudo. Assim, fica reforçado que é possível conduzir uma sequência dessa natureza. Além disso, a aula torna-se interessante, pois o pesquisador, no papel de professor, tornou-se mediador na construção de conhecimentos e o professor, dessa turma, se envolveu e se entusiasmou com abordagens como esta.

Podemos reforçar assim, que incluir sequências didática sobre um determinado conteúdo utilizando softwares, como o Graphmática, em atividades nas modalidades inicial ou continuada, é um suporte fundamental para o desenvolvimento profissional do professor. Sendo assim, é preciso repensar a formação inicial dos professores, que muitas vezes não tem acesso a tecnologia e seus usos durante essa etapa e, também, investir na criação de um sistema de formação continuada que tenha como base a reflexão sobre a prática do professor. Além disso, destacamos que tais iniciativas, sempre que possível deverão ser desenvolvidas no próprio ambiente escolar, envolvendo os alunos, professores, coordenadores e gestores. Desse modo, acreditamos que por meio do desenvolvimento profissional dos professores, estes melhorem e ampliem o leque de conhecimentos, a partir da participação e da reflexão das oportunidades de formação em serviço dentro das próprias escolas.

\section{Referências}

Bairral, M.A., \& Abreu, P.F. (2009). Política de inclusão digital mediante a informática educativa: um estudo com professores 
de matemática, refletindo sobre objetivos do Cabri, do Excel e do Powerpoint. Zetetike (17), 151-180.

Borba, M. C., \& Penteado, M.G. (2005) Informática e Educação Matemática. Belo Horizonte: Autêntica.

Braga, M.L.S. (1999). As Três Categorias Peircianas e os Três Registro Lacanianos. Psicologia USP. 10 (2), 81-91.

Brasil. (1998) Secretaria de Educação Fundamental. Parâmetros Curriculares Nacionais: Matemática. Brasília: MEC/SEF.

Brasil. (1999). Ministério da Educação e Cultura. Parâmetros Curriculares Nacionais: Ciência da Natureza, Matemática e suas Tecnologias - Ensino Médio, v. 3. Brasília; MEC/SEB.

Chevallard, Y, Bosch, M, \& Gascón, J. (2001). Estudar Matemáticas: o elo perdido entre o ensino e a aprendizagem. Porto Alegre: Artmed.

Coelho Netto, J. T. (2014). Semiótica, comunicação e informação. São Paulo: Perspectiva.

D’Oliveira, A. M. (1989). Peirce: vida e obra. In: C.S Peirce, Escritos coligidos. São Paulo: Nova Cultural.

Eco, U. (1989). Sobre os espelhos e outros ensaios. Rio de Janeiro: Nova Fronteira.

Ezpeleta, J, \& Rockwell, E. (1986). Pesquisa participante. São Paulo: Editores Associados.

Martins, W.A. (2015). Semiótica de Charles Peirce: O ícone e a primeiridade. Revista Contemplação. 12, 237-250.
Minayo, M.C. S. (2014). O desafio do conhecimento: pesquisa qualitativa em saúde. São Paulo: HUCITEC.

Moimaz, E.R, \& Molina, A. H. (2018, maio). A Contribuição da Semiótica Peirceana para Análise da Pintura Histórica. Anais do Encontro Nacional de Estudos da Imagem. Londrina,PR,Brasil, 2. Recuperado de www.uel.br/eventos/ eneimagem/anais/trabalhos/pdf/Moimaz_erica\%20Ramos. $p d f$.

Peirce, C.S. (1989). Escritos Coligidos. São Paulo: Nova Cultural.

Penteado, M. G. (1999). Novos atores, novos cenários: discutindo a inserção dos computadores na profissão docente. Pesquisa em educação matemática: concepções e perspectivas, (pp.297-313). São Paulo: Unesp.

Roxo, E. (1937). A matemática na educação secundaria. Rio de Janeiro: Companhia Editora Nacional.

Santaella, L. (2004). Navegar no ciberespaço: o perfil cognitivo de leitor imersivo. São Paulo: Paulus.

Santos, V, Faria, A. H. (2017). Uso de tecnologias e jogos eletrônicos por crianças: uma "nova" parte da história. Anais Eletrônicos do IV EHECO, Campo Grande, MS, Brasil, 4. Recuperado de http://eheco.com.br/ARQUIVOS/ANAIS/ Vanessa\%20Santos\%20-\%20Adriana\%20Horta\%20Faria. pdf

Toranzos, F. I. (1963). Enseñanza de la Matemática. Buenos Aires: Editorial Kapelusz. 